C2008 IEEE. Personal use of this material is permitted. However, permission to reprint/republish this material for advertising or promotional purposes or for creating new collective works for resale or redistribution to servers or lists, or to reuse any copyrighted component of this work in other works must be obtained from the IEEE. 


\title{
Superconducting Magnetic Energy Storage Unit, an Efficient Energy Technology for Power Systems
}

\author{
A. Abu-Siada, S. Islam \\ Curtin University of Technology, Australia
}

\begin{abstract}
This paper discusses application of Superconducting Magnetic Energy Storage (SMES) unit to improve power system performance. The application of SMES unit in mitigating voltage sags and in damping dynamic oscillations in power systems is discussed. To show the effectiveness of the proposed controller in providing continuous voltage regulation and in enhancing power system dynamics, a three-phase short circuit is applied to the system and simulation is carried out with and with no SMES connected to the system. The results of these investigations are studied using the well-developed graphic facilities available in an industry standard power system package, namely PSCAD/EMTDC. Results have shown that SMES unit can effectively improve system stability and power quality of power systems.
\end{abstract}

\section{INTRODUCTION}

As sensitive loads such as computerised machines, computers and medical instruments increase from day to day power quality issues are becoming more important. Power quality problems generally appear in the form of voltage sags, transients and harmonics. These problems can lead to severe consequences to the sensitive loads as well as the power system. Many countermeasures have been proposed in the literatures to mitigate voltage sags and increase system damping [1-3]. This paper discusses the SMES unit to be one possible solution to the problem. SMES has by far the fastest response time compared to any other storage systems. One of the most basic properties of the superconducting materials is the ability to give up electrical resistivity. Since the coil is loss-less, the SMES can control its active and reactive powers quickly and simultaneously with very high efficiency (over 95\%). Due to this characteristic, SMES applications in power systems have been given a great attention by electric utilities. These applications include load levelling, dynamic stability, transient stability, voltage regulation, and reactive power compensation, correction of power factor, elimination of current harmonics, frequency regulation, transmission line stabilizer, and power quality improvement [4-7]. This paper shows the different applications of SMES units to improve power system performance. PSCAD/EMTDC electromagnetic transient program is used to simulate the system under study [8,9]. Simulations were carried out with and with no SMES connected to the system. Next section provides a brief description of the system under study as well as the SMES unit, then, the suggested control algorithm is provided and finally the simulation results and conclusions are discussed.

\section{SYSTEM UNDER STUDY}

Figure 1 shows the system under study, which consists of a six-pulse AC/DC converter station connected to a synchronous machine that is connected to an infinite bus system via a transformer and a transmission line. The shaft system of the turbine generator unit consists of four masses; high-pressure turbine (HP), low-pressure turbine (LP), generator rotor (Gen) and the exciter (Ex). Also, a local ac load and a group of harmonic filters are connected to the ac bus of the converter station. The suggested location of the SMES unit is at the terminal of the synchronous machine to provide adequate damping for the turbine generator set. To carry out the investigations, a non-linear model of the system is developed to incorporate the interaction between the electric network and the torsionally oscillating shaft system of the turbine-generator under investigation. The system has been simulated such that all the nonlinearities such as the exciter ceiling voltage limit and the current limit of the superconducting inductor have been included.

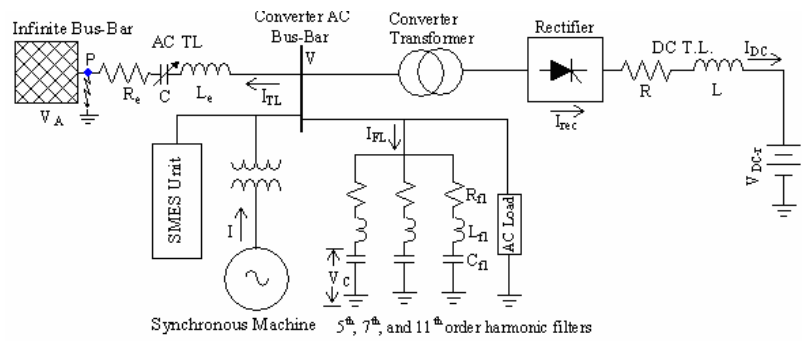

Fig. 1 Single line diagram of the system under study

The SMES unit (Fig. 2) consists of a high temperature superconductor (HTS) coil that can be maintained within the superconductivity state using liquid nitrogen which is less expensive than the liquid helium used in low temperature superconductors (LTS). The superconductor coil is interfaced with a power system through a pair of bi-directional AC/DC converters connected at the lowtension sides of two separate $\mathrm{Y}-\mathrm{Y}, \mathrm{Y}-\Delta$ transformers. Each converter station is modelled as a three-phase, 6pulse forced commutated GTO bridge [10]. 


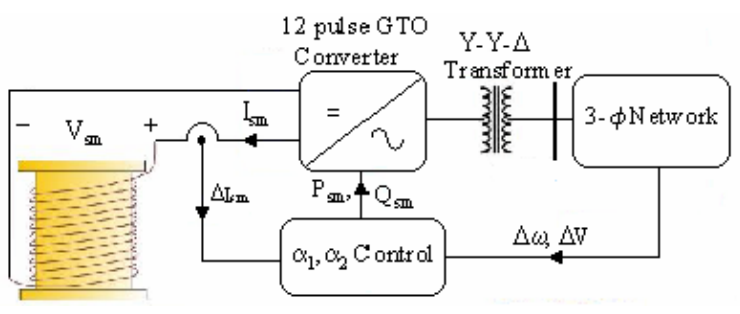

Fig. 2 Schematic diagram of the SMES unit

The converter dc output current $\mathrm{I}_{\mathrm{sm}}$ being unidirectional, the control for direction of the inductor power flow $\mathrm{P}_{\mathrm{sm}}$ and $\mathrm{Q}_{\mathrm{sm}}$, is achieved by continuously regulating the firing angles $\alpha_{1}$ and $\alpha_{2}$. For initial charging of the SMES unit, the bridge voltage $\mathrm{V}_{\mathrm{sm}}$ is held constant at a suitable positive value. The inductor current $I_{s m}$ raises and magnetic energy $\mathrm{W}_{\mathrm{sm}}$ is stored in the inductor. When the inductor current reaches its rated value $I_{\text {smo, it is }}$ maintained constant by lowering the voltage across the inductor to zero. The SMES unit is then ready to be coupled to a power system. Usually the SMES is suggested to be placed as close as possible to the load centre in order to provide instantaneously power modulation. However, for improvement of power system damping, the location is near the generator terminal.

\section{CONTROL ALGORITHM}

The rotor angle $\delta$ of the synchronous generator is governed by the swing equation [11]:

$$
\frac{H}{\pi f} \frac{d^{2} \delta}{d t^{2}}=P_{a}=P_{m}-P_{e}
$$

where $P_{m}$ is the shaft mechanical input power, $P_{e}$ is the electrical output power, $\mathrm{H}$ is the inertia constant of the generator in per unit of system base and $f$ is the system frequency. Under steady state operation of the generator $\mathrm{P}_{\mathrm{m}}$ and $\mathrm{P}_{\mathrm{e}}$ are equal and the accelerating power $\left(\mathrm{P}_{\mathrm{a}}\right)$ is zero. In this case there is no acceleration or deceleration of the rotor masses and the resultant constant speed is the synchronous speed. On occurrence of a fault, the generator rotor angle $\delta$ undergoes oscillation about the synchronous position and the electrical output power of the machine varies with $\delta$. When the machine accelerates, its rotating parts absorb the excess energy. When it decelerates, the rotating parts release energy due to its inertia. A synchronous machine may have mechanical damping adequate for the machine itself, but not sufficient for the machine operating in a large electric power system [12]. If no adequate damping has been provided, system may lose its stability and severe damage may be occurred. Therefore, supplementary damping must be sought. Connecting the SMES unit to the generator bus to provide the required extra damping, the swing equation is modified to take into account the presence of SMES as follows:

$$
\frac{H}{\pi f} \frac{d^{2} \delta}{d t^{2}}=P_{a}=P_{m}-P_{e}-P_{s m}
$$

where $\mathrm{P}_{\mathrm{sm}}$ is the power absorbed (positive) or released (negative) by the SMES coil. With the SMES unit connected to the generator terminals, the generator acceleration is zero in the normal operating conditions and the SMES does not exchange any power i.e. $\mathrm{P}_{\mathrm{sm}}=0$. On occurrence of a fault, both rotor mass and SMES absorb power when the machine accelerates and release power when the machine decelerates. In order to derive the independent control of active and reactive power, assume, for simplicity, the equivalent commutating resistance are neglected. According to the circuit analysis of converter, the voltage $\mathrm{V}_{\mathrm{sm}}$ in the $\mathrm{DC}$ side of the 12-pulse converter is expressed by [13]:

$$
V_{s m}=V_{s m o}\left(\cos \alpha_{1}+\cos \alpha_{2}\right)
$$

where $\mathrm{V}_{\text {smo }}$ is the ideal no-load maximum DC voltage of the 6-pulse bridges. The current and voltage of the superconducting inductor are related by:

$$
I_{s m}=\frac{1}{L_{s m}} \int_{t_{o}}^{t} V_{s m} d \tau+I_{s m o}
$$

where $I_{\text {smo }}$ is the initial current of the inductor. Because $\mathrm{V}_{\mathrm{sm}}$ is a function of $\alpha_{1}$ and $\alpha_{2}$, its value can be varied in a wide range of positive and negative values via the control of $\alpha_{1}$ and $\alpha_{2}$. $I_{\mathrm{sm}}$ is always unidirectional. Thus reversibility as well as magnitude control of power flow is achieved continuously and smoothly through the control of the firing angles $\alpha_{1}$ and $\alpha_{2}$. Equation (3) shows that the SMES unit can operate in three modes: (i) The standby mode at firing angles equal to $90^{\circ}$, where the voltage across the SMES coil is equal to zero and the SMES coil current is at its rated value, consequently, there will be no energy transferred (ii) Charging mode at firing angles less than $90^{\circ}$, where power will be absorbed from the AC system (iii) Discharging mode at firing angles greater than $90^{\circ}$, where power will be injected in to the system. Adjusting the values of the firing angles can control the rates of charging and discharging. At any time, the active and reactive power delivered or absorbed by the SMES unit is given by:

$$
\begin{aligned}
& P_{s m}=V_{s m o} I_{s m}\left(\cos \alpha_{1}+\cos \alpha_{2}\right) \\
& Q_{s m}=V_{s m o} I_{s m}\left(\sin \alpha_{1}+\sin \alpha_{2}\right)
\end{aligned}
$$

Using equations (5) and (6), the firing angles of the converter under four-quadrant operation can be calculated as $[14,15]$ :

$$
\begin{aligned}
& \alpha_{1}=\cos ^{-1}\left(\frac{P_{s m}}{\sqrt{P_{s m}^{2}+Q_{s m}^{2}}}\right)+\cos ^{-1}\left(\frac{\sqrt{P_{s m}^{2}+Q_{s m}^{2}}}{2 V_{s m o} I_{s m}}\right) \\
& \alpha_{2}=\cos ^{-1}\left(\frac{P_{s m}}{\sqrt{P_{s m}^{2}+Q_{s m}^{2}}}\right)-\cos ^{-1}\left(\frac{\sqrt{P_{s m}^{2}+Q_{s m}^{2}}}{2 V_{s m o} I_{s m}}\right)
\end{aligned}
$$

In order to use the SMES unit as a torsional mode stabilizer, the active power $\mathrm{P}_{\mathrm{sm}}$ transferred by the converter is controlled continuously depending on the measured speed deviation of the turbine-generator rotor. The reactive power control is usually for the purpose of voltage sag mitigation. Then the reactive power $\mathrm{Q}_{\mathrm{sm}}$ transferred in the converter is controlled continuously depending on the measured voltage deviation of the generator bus terminal. Figure 2 shows the SMES control module with P-Q simultaneous control scheme. 
The generator shaft speed deviation $(\Delta \omega)$ and the deviation in SMES coil current $\left(\Delta \mathrm{I}_{\mathrm{sm}}\right)$ are fed to generate the active power $\left(\mathrm{P}_{\mathrm{sm}}\right)$ while the generator terminal voltage deviation $(\Delta \mathrm{V})$ is sensed to generate the reactive power $\left(\mathrm{Q}_{\mathrm{sm}}\right)$. $\mathrm{P}_{\mathrm{sm}}$ and $\mathrm{Q}_{\mathrm{sm}}$ are respectively, the actual active and reactive powers inputted to the SMES unit. Knowing $\mathrm{P}_{\mathrm{sm}}, \mathrm{Q}_{\mathrm{sm}}$ and the present value of the inductor current $\mathrm{I}_{\mathrm{sm}}$, the firing angles of the converter stations can be calculated as given in (7) and (8).

\section{SIMULATION RESULTS}

In all the cases studied in this paper, it is assumed that the turbine-generator is operating at steady state delivering rated power to the infinite-bus system. To verify that condition the multi-mass system has been enabled at $0.1 \mathrm{~s}$. The plot time step is $0.05 \mathrm{~s}$ for all the figures given in this paper.

\section{Dynamic Stability}

To demonstrate the capability of the SMES unit in improving the dynamic stability of power systems and in mitigation of voltage sags, a three-phase fault is created at a point $\mathrm{P}$ of Fig.1 very close to the infinite bus bar. The fault is applied at $\mathrm{t}=1 \mathrm{~s}$ and is assumed to last for 5 cycles, i.e. $0.083 \mathrm{~s}$ (on a $60 \mathrm{~Hz}$ basis). When there is no SMES connected to the power system, the system response is depicted in Fig. 3. The first plot shows the ac voltage at bus $\mathrm{A}$, the second plot shows the speed of the synchronous machine, and the last three plots show the electrical torque of the synchronous machine $\left(\mathrm{T}_{\mathrm{e}}\right)$, and the torsional torques induced in the turbine generator shaft $\left(T_{h l}\right.$ that induced in the segment of the shaft between high and low pressure turbines and $T_{\mathrm{lg}}$ that induced in the segment of the shaft between low pressure turbine and the synchronous machine) respectively. When the SMES is connected to bus A, the response is given in Fig. 4. The voltage across the SMES coil terminal $\left(\mathrm{V}_{\mathrm{sm}}\right)$ and its corresponding SMES current $\left(\mathrm{I}_{\mathrm{sm}}\right)$ are shown respectively in Fig. 5. The results are discussed below.

(i) Case with SMES 'off'

When the SMES is kept off, It can be shown that during the fault, the amount of voltage sag is about $65 \%$ of the voltage nominal value during the pre-fault period. The speed of the machine reaches to a crest value $\pm 2.5 \%$ of its nominal value. The waveforms show that the system under such fault conditions is unstable and the generator shaft may be damaged due to the high torsional forces applied to it during the fault.

(ii) Case with SMES 'on'

By connecting the SMES to bus A and for the same fault period, the response of the system is shown in Fig. 4. From the Figure, the amount of voltage sag is only $25 \%$. The machine speed oscillation does not exceed than $\pm 0.5 \%$ of its nominal value. Using an SMES unit will reduce the high torsional forces on the turbine-generator shafts to almost normal steady state values.

A comparison of cases (i) and (ii) shows that, an SMES connected to a bus near the generator gives very effective results in damping electromechanical transient oscillations caused by a three phase fault. The very effective voltage regulation provided by the SMES can be clearly appreciated.
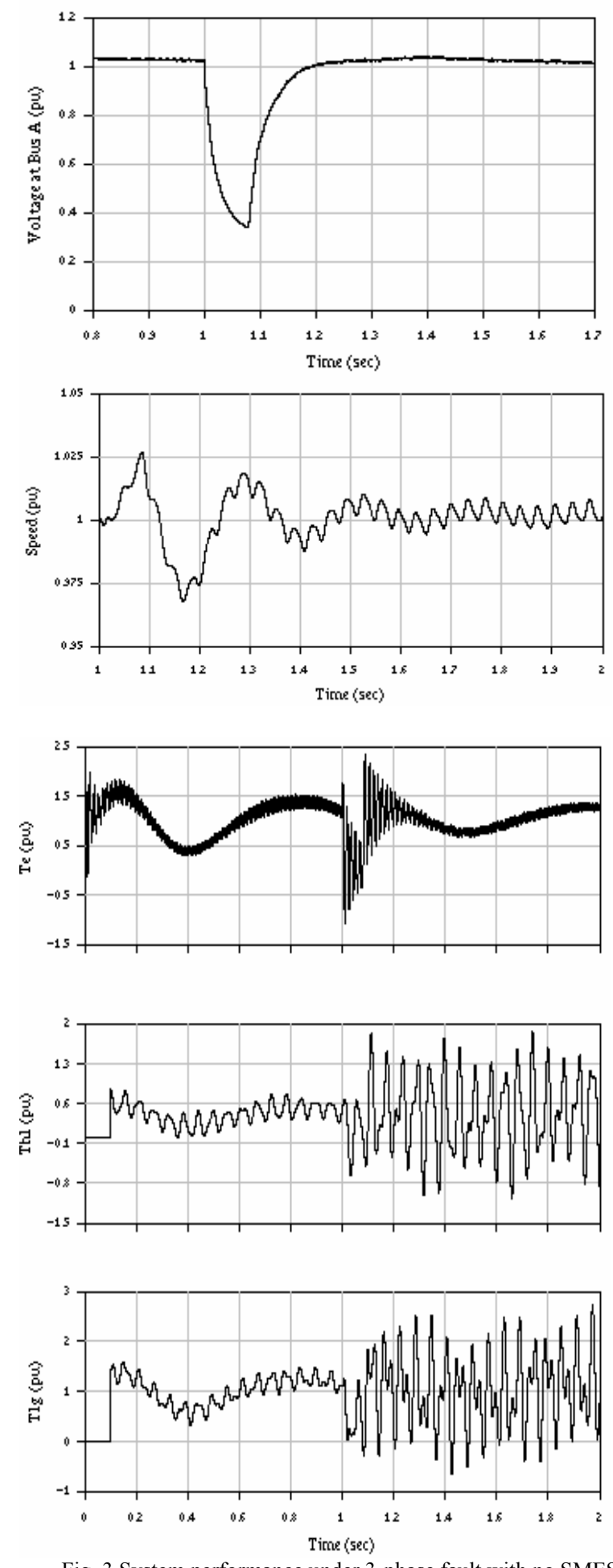

Fig. 3 System performance under 3-phase fault with no SMES

Figure 5 shows that the unit is first charged and connected to the system at $t=0.6 s$. From $t=0.6 s$ to $t=1 s$, there is a transient slight increase in the SMES current. When the fault occurs at $\mathrm{t}=1 \mathrm{~s}$ the current decreases resulting in negative slope $(\mathrm{di} / \mathrm{dt})$ and consequently the voltage across the coil $\left(\mathrm{V}_{\mathrm{sm}}=\mathrm{L}^{*} \mathrm{di} / \mathrm{dt}\right)$ is turning 
negative. The power now is being delivered from the unit to the system resulting in stabilising the torsional torques. The voltage across the coil returns back to zero value at $\mathrm{t}=1.6 \mathrm{~s}$. Once a system with SMES has regained post fault stability, the SMES need not be kept 'on' continuously, but turning it off can reduce the generator rotor oscillations to some extent. It also reduces the operating expenses of the SMES [16].
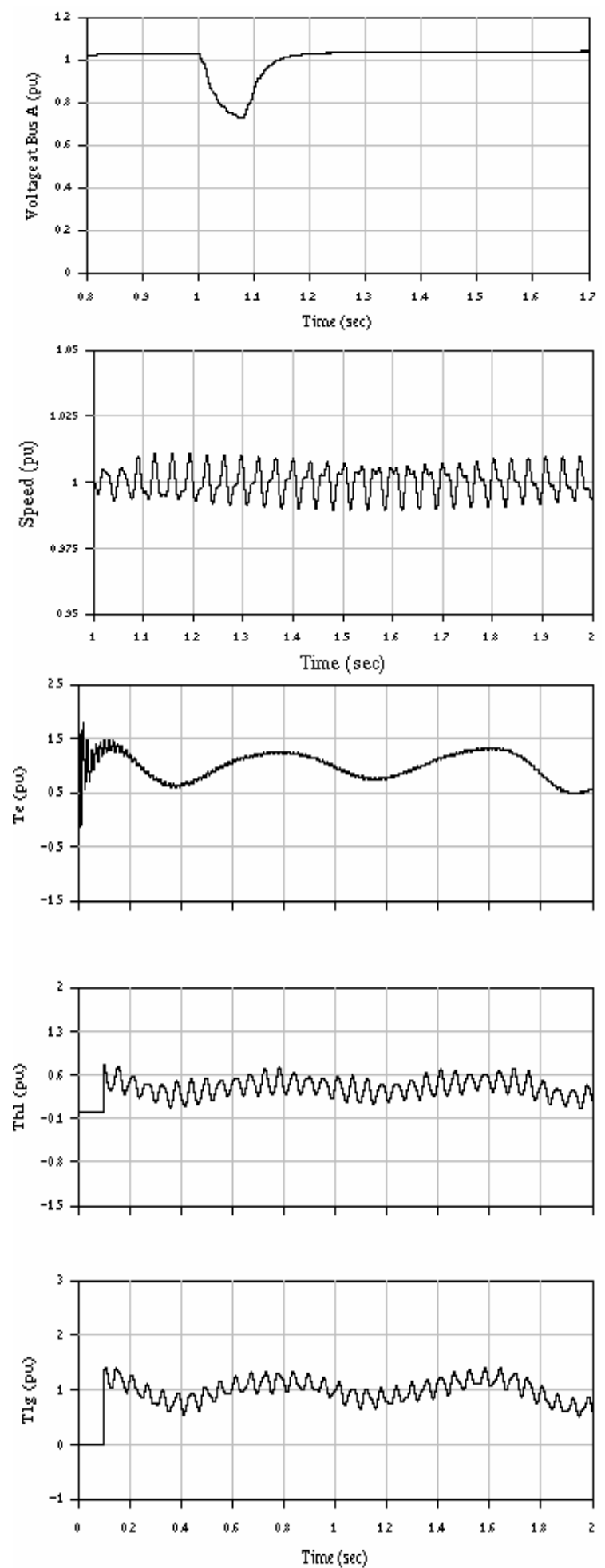

Fig. 4 System performance under 3-phase fault with SMES connected to bus $\mathrm{A}$
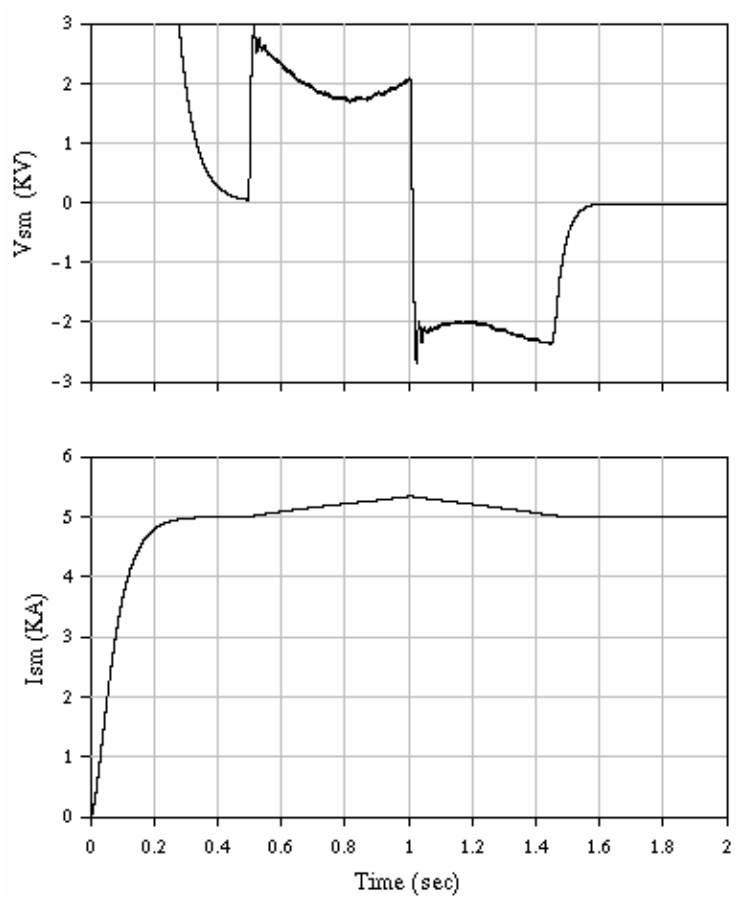

Fig. 5 Voltage across and current through SMES coil

\section{Damping of Sub-Synchronous Resonance (SSR)}

Eigenvalue analysis is performed on the system under study to demonstrate the effectiveness of the proposed controller in damp effectively all SSR oscillation modes.

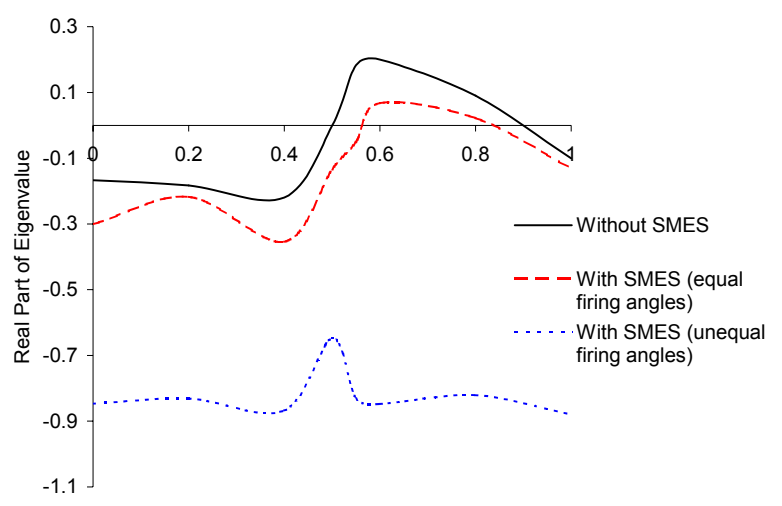

Xc / XI Compensation Ratio

Fig. 6 Real part of electromechanical mode eigenvalues under different $\mathrm{X}_{\mathrm{C}} / X_{L}$ compensation

Figure 6 plots the real part of the torsional mode 1 under different degrees of series compensation $\left(X_{C} / X_{L}\right)$ for three control schemes (without SMES, with the SMES unit under equal $\alpha$-mode and with an SMES unit under unequal $\alpha$-mode). It can be seen that, without the SMES unit, mode 1 is stable up to $50 \%$ compensation degree. With the SMES unit under equal- $\alpha$ mode of operation, the stability margin has been extended to $55 \%$ compensation degree. However, with the SMES unit under unequal- $\alpha$ mode of operation, the torsional mode 1 is always stable at any compensation degree. It is valuable to note that using an SMES unit under unequal$\alpha$ mode of operation will enhance all the torsional modes of the turbogenerator. Damping of the electromechanical 
mode is simultaneously greatly improved. The most widely used power system stabilizer (PSS) is not needed to damp the low frequency oscillation since the SMES unit under unequal- $\alpha$ mode can provide enough damping torque.

\section{Application of SMES unit in HVDC systems}

This section discusses the use of SMES unit in an HVDC system. A flashover across a non-conducting valve of the converter station is considered with and without the SMES unit. Flashover results in a line-to-line fault with a very large over-current in the conducting valve on the same side of the bridge. The magnitude of this large current is dependent on the instant of the flashover. In the investigations conducted in this section, the flashover is assumed to occur at the instant which gives the maximum fault current i.e. just at the instant of completion of commutation of the two valves.
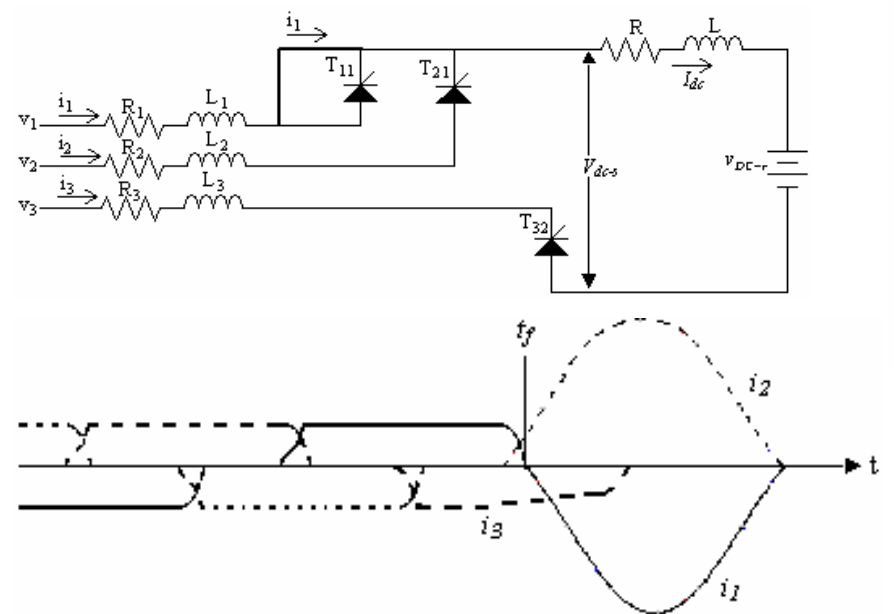

Fig. 7 Equivalent circuit and rectifier currents during a short circuit across a non-conducting valve

With reference to Fig. 7, if a flashover occurs across valve $\mathrm{T}_{11}$ at the instant $t_{f}$ at which commutation from valve $T_{11}$ to valve $T_{21}$ is completed while valve $T_{32}$ is conducting, the short circuit on phases $\mathrm{a}$ and $\mathrm{b}$ of the converter transformer is renewed. In this case, currents $i_{1}$ and $i_{2}$ continue as the same offset sine waves that they were during the normal commutation. On the other hand, the dc voltage $V_{d c-s}$ collapses and the dc current $\left(I_{d c}=-i_{3}\right)$ decreases to zero. Assuming that the fault is detected and all non-conducting valves are blocked successfully, valve $T_{32}$ will stop conducting as its current reaches zero and valve $T_{11}$ and $T_{21}$ still constitute a line-to-line fault on the converter transformer. When $i_{1}$ and $i_{2}$ reach zero simultaneously, valve $T_{21}$ will stop conducting. Figure 8 illustrates the transient time responses of the AC/DC system during a flashover across a non-conducting valve without connecting the SMES unit. The fault is assumed to occur after the dc current has reached its steady state value after switching in the converter station. Moreover, it is assumed that the flashover occurs across valve $T_{11}$ at the instant $t_{f}$ (Fig. 7). It can be seen from Fig. 8 that the rectifier currents $i_{1}$ and $i_{2}$ reach simultaneously a crest value $\left(i_{\text {fmax }}=11.6\right.$ p.u. $)$ much higher than their steady state value $\left(i_{1 \max }=i_{2 \max }=I_{d c}=1.4\right.$ p.u.) during normal operation. It is worthwhile to mention that the smaller the firing delay angle, the higher is the value of $i_{\text {fmax }}$ which reaches to its maximum value at $\alpha=0^{\circ}$.
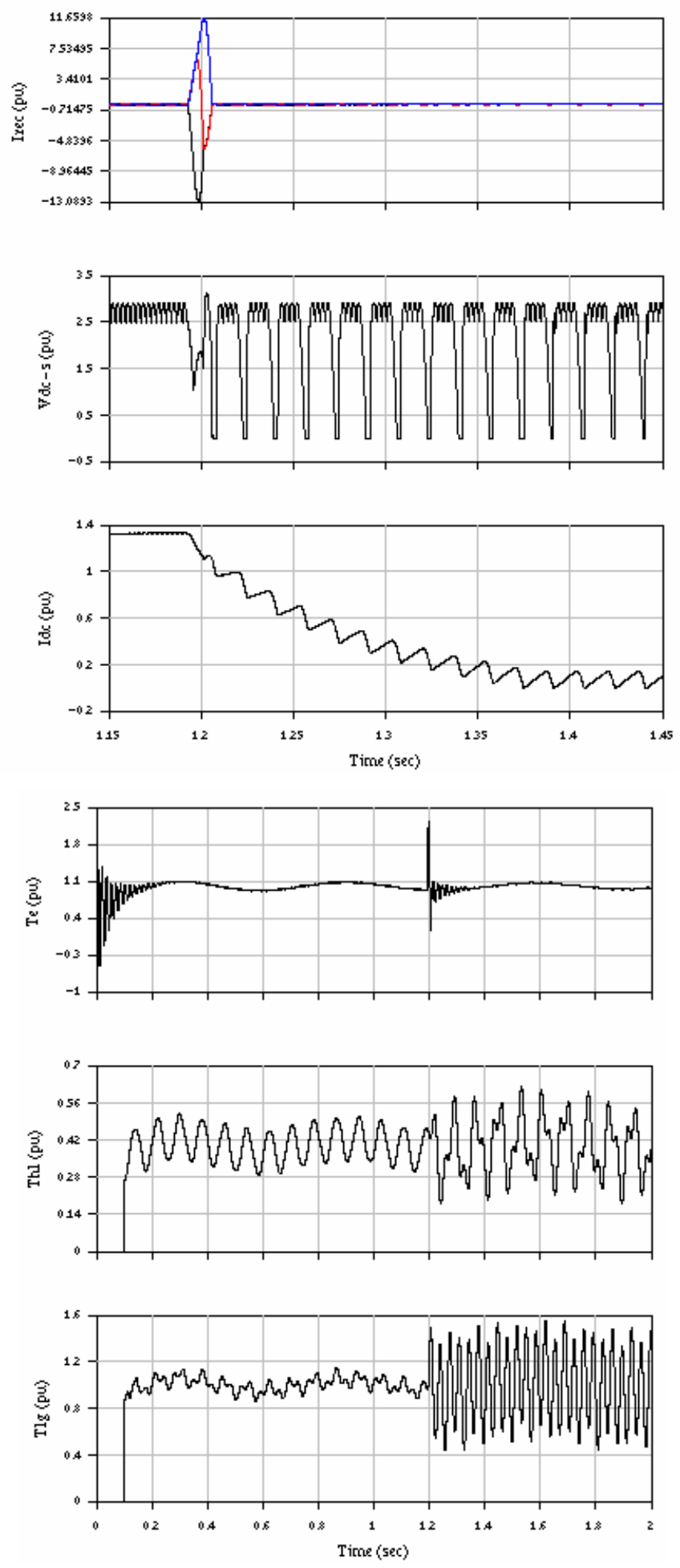

Fig. 8 Transient time responses of the system during flashover without the SMES unit $\left(t_{f}=1.189 \mathrm{~s}\right)$

Figure 8 shows that prior $t_{f}$, the torsional torques follow the pattern of the normal operation. As the commutation from valve $T_{11}$ to valve $T_{21}$ starts, the turbine-generator responds to a line-to-line fault condition. The occurrence of the flashover just at the end of the commutation 
period sustains the fault. When $i_{1}$ and $i_{2}$ reach zero and valve $T_{21}$ stops conducting, the fault is physically cleared with respect to the turbine-generator. It can be seen from the Figure that the superimposition of two successive torsional shocks due to the fault and the ensuing clearing on the already oscillating shaft system due to switching in the HVDC converter station results in a high increase in the turbine-generator torsional torques. The percentage increase in the maximum torsional torques induced in the (LP-GEN) and (HP-LP) shaft sections are $51 \%$ and $33 \%$ respectively.
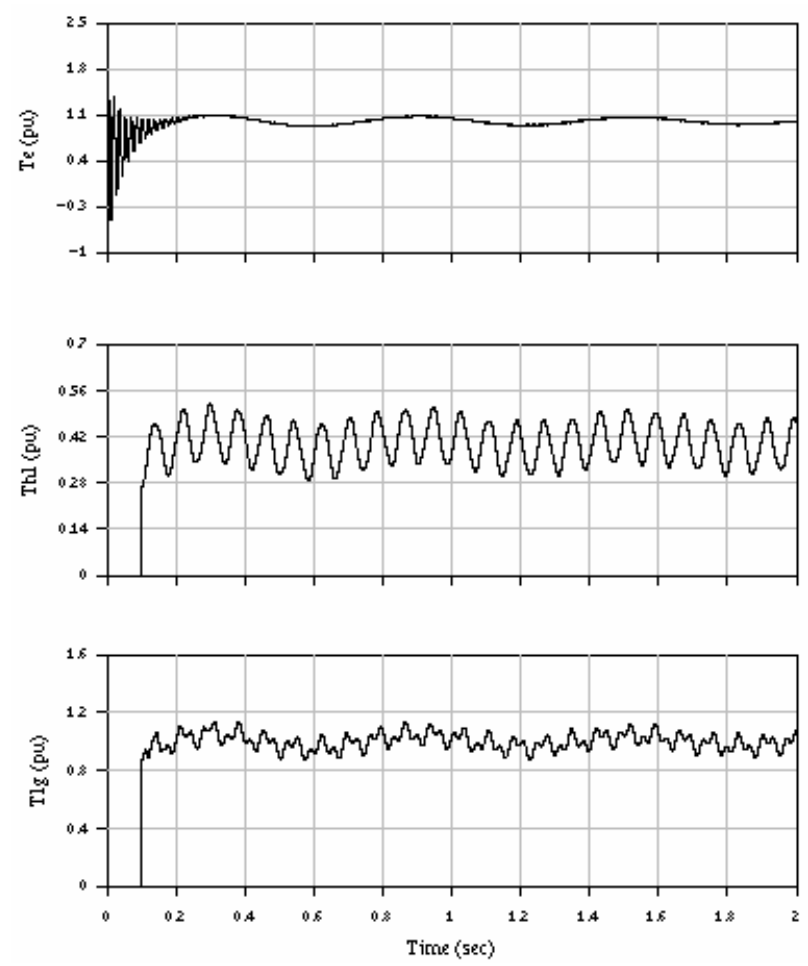

Fig. 9 Transient time responses of the system during flashover with the SMES unit $\left(t_{f}=1.189 \mathrm{~s}\right)$

Figure 9 shows the turbine-generator torques during a flashover across a non-conducting valve with the SMES unit connected to the generator bus. It can be seen that, by connecting the SMES, the turbine-generator torques follows almost the same pattern of the normal operation of the HVDC converter station.

\section{CONCLUSIONS}

This paper presents the different application of SMES unit to improve power system performance. It has been found that the SMES can be very effective in damping power system oscillation and enhancing its dynamic stability. It has been shown also that SMES can provide a very effective voltage regulation to the ac grid and hence keeping its power quality. The application of SMES unit can be extended to HVDC system. Results show its effectiveness in enhancing the dynamic Stability of the studied system under flashover fault in the converter station of the HVDC system. With continued research on superconducting materials, the cost of SMES is decreasing so that it will be commercially available and cost-competitive option than other power system stabilisers.

\section{REFERENCES}

1. Larsen, E.V. and D.A. Swann, Applying power system stabilizers. IEEE Trans. power Appar. and Syst., 1981. PAS-100: p. 30173046.

2. S.C. Tripathy, T.S.Bhatti, et al., Sampled data automatic generation control analysis with reheat steam turbines and governor dead-band effect. IEEE Trans. power Appar. and Syst., 1984. PAS-13: p. 1045-1051.

3. Stemmeler, H. and G. Guth, The thyristor controlled static phase-shifter a new tool for power flow control in ac power system. Brown Boveri Review, 1982. 69: p. 73-78.

4. C.Rehtanz, Systematic Use of Multifunctional SMES in Electric Power System. IEEE Transactions on Power Systems, 1998. vol.14(No.4): p. 1422-1427.

5. Malozemoff, A.P., et al., Power Applications of HighTemperature Superconductors: Statues and Perspectives. IEEE, 2002. 12(1): p. 778-781.

6. Mikkonen, R., Highlights of SC Power Applications in Europe. IEEE Transactions on Applied Superconductivity, 2002. 12(1): p. 782-787.

7. Y.Shirai, T.N., and M.Yamada, Experimental study on stability evaluation in parallel running of superconducting generator and a SMES. IEEE Transaction on Applied Superconductivity, 2002. 12(1): p. 890-781.

8. Manitoba HVDC Research Centre, PSCAD/EMTDC:

Electromagnetic transients program including dc systems. 1994.

9. Gole, A.M., et al., A graphical electromagnetic simulation laboratory for power systems engineering programs. IEEE Trans. Power Syst., 1996. 11: p. 599-606.

10. Ise, T., Y. Murakami, and K. Tsuji, Simultaneous Active and Reactive Power Control of Superconducting Magnetic Energy Storage Using GTO Converter. IEEE Trans., 1986. Vol. PWRS3: p. 1418-1425.

11. Stevenson W.D, Elements of power System Analysis. Fourth ed. 1982: McGraw-Hill International Book Company.

12. Yu, Yao-Nan, Electric Power System Dynamics. 1983.

13. N., Mohan, Undeland T.M., and Robbins W.P., Power Electronics: Converters, Applications, and design. second ed. 1995: John Willy \& Sons.

14. Rabbani, M.G., J.B.X. Devotta, and S.Elangovan, Application of simultaneous active and reactive power modulation of SMES Unit under unequal $\alpha$-mode for power system stabilization. IEEE Trans. on Power System, 1999. 14(2): p. 547-552.

15. Abu-Siada, A., W.W.L. Keerthipala, and W.B. Lawrance, Application of a Superconducting Magnetic Energy Storage unit to improve the Stability Performance of Power Systems. IEEE ccece02 Proceedings; ISBN: 0-7803-7514-9, 2002. 1: p. 212217.

16. S.S.Ahmed, S.Bashar, et al., Use of superconducting magnetic energy storage device in a power system to permit delayed tripping. IEE Proc.-Gener. Transm. Distrib., 2000. 147(5): p. 269-273. 